\title{
CAPITAL MISALLOCATION AND AGGREGATE FACTOR PRODUCTIVITY
}

\author{
Costas Azariadis \\ Washington University \\ LEO KAAS \\ University of Konstanz
}

We propose a sectoral-shift theory of aggregate factor productivity for a class of multisector economies with AK technologies and a constant production possibilities frontier. Loans are partly secured by collateral and partly based on reputation. We find that both the growth rate and total factor productivity (TFP) respond to random and persistent endogenous fluctuations in the sectoral distribution of physical capital, which, in turn, responds to reversible exogenous shifts in relative sector productivities. Endogenous debt limits on secured and unsecured loans slow down capital reallocation, preventing the equalization of risk-adjusted equity yields across sectors. Economywide factor productivity and the aggregate growth rate are both negatively correlated with the dispersion of sectoral rates of return, sectoral TFP, and sectoral growth rates. We also find highly volatile limit cycles in economies with small amounts of collateral.

Keywords: TFP, Misallocation, Sectoral Shocks

\section{INTRODUCTION}

National income accounting exercises conducted by Klenow and Rodriguez-Clare (1997), Hall and Jones (1999), and Chari et al. (2007) unanimously conclude that total factor productivity (TFP) is of cardinal importance for both long-run growth and business cycles, including economic depressions. There is less agreement about the source of productivity differentials. Suggestions range widely from the differences in broadly defined social infrastructure advocated by Hall and Jones, to the technology adoption barriers proposed by Parente and Prescott (1999), to the labor market frictions studied in Lagos (2006).

We thank Carlos Garriga, Michele Boldrin, conference participants at SED 2009 and at EEA-ESEM 2009, and seminar participants in Aix-Marseille, Amsterdam, Athens (AUEB), Carbondale (SIU), Kyoto, Milwaukee (UW), Munich, Rome (Luiss and EIEF), Strasbourg, at the IMF, the European Central Bank, and at the Federal Reserve Banks of Philadelphia and St. Louis for many valuable comments. Leo Kaas thanks the German Research Foundation (grant No. KA 1519/3) for financial support and the Federal Reserve Bank of St. Louis for financial support and hospitality. Costas Azariadis thanks LUISS and Ente Enaudi for their hospitality. Address correspondence to: Leo Kaas, Department of Economics, University of Konstanz, Box D145, 78457 Konstanz, Germany. E-mail: leo.kaas@uni-konstanz.de. 
This paper is a theoretical investigation of an entirely different mechanism based on the interaction of asset-based and non-asset-based loans. In this environment, credit market frictions limit capital mobility and slow the movement of resources from temporarily less to temporarily more productive sectors, and more generally, from temporarily low to temporarily high valuations. Our main contribution is to clarify the forces responsible for fluctuations in collateralized and reputational lending and explore their implications for aggregate factor productivity. We are pushed in this direction by much evidence connecting poor economic performance with capital misallocation. Chari et al. (2007) find that financial frictions, defined as "efficiency wedges" that distort the allocation of intermediate inputs among firms, ${ }^{1}$ account for $60-80 \%$ of the U.S. output drop in the 1929-1933 depression and the 1979-1982 recession, and also for $73 \%$ of the variance in detrended U.S. output from 1959 to 2004. Eisfeldt and Rampini (2006) find that capital reallocation among U.S. firms - defined as sales and acquisition of property, plant and equipment-makes up nearly $25 \%$ of total investment on average. There are also strong indications that macroeconomic volatility is connected with the dispersion of both sectoral productivities and sectoral rates of return on capital. $^{2}$

We describe sectoral shifts as idiosyncratic technology shocks in a class of simple economies populated by identical infinitely lived households and consisting of finitely many sectors that produce the same consumption good. Capital is the only input in production, which means that we focus on the misallocation of investment and ignore potentially larger problems stemming from imperfectly functioning labor markets. Sectoral technologies are assumed to be AK with random idiosyncratic productivities and a constant aggregate production possibility frontier, that is, a fixed value for the maximal idiosyncratic productivity. We ignore declining and expanding industries, assuming instead that all sectoral shocks are temporary and reversible.

An ideal economy of this type without any financial frictions would exploit its unchanging aggregate production possiblities to the fullest by moving all physical capital instantly to the most productive sector and delivering to its population a constantly growing stream of aggregate output and individual consumption. In what follows, surplus capital from less productive sectors is in the form of collateral loans, as suggested by Kiyotaki and Moore (1997), secured by an exogenous fraction $\lambda \in[0,1]$ of the borrower's total resources, and also in the form of unsecured reputational loans, as in Bulow and Rogoff (1989), which punish defaulters with perpetual exclusion from future borrowing. Both types of loans require endogenous forward-looking debt limits, which rule out default when asset markets are complete. ${ }^{3}$ When these limits bind, they slow capital reallocation and prevent rates of return on capital from reaching equality across all sectors.

Generous debt limits are typical outcomes for economies with abundant collateral, that is, a relatively high value of $\lambda$, and with a shared belief among debtors that substantial lines of unsecured credit will continue to be available in the future. Any deterioration in the amount of collateral or in the expected flow of future 
unsecured credit will tighten current debt limits and impede the flow of capital from lower to higher valuations.

Low capital mobility tends to spell trouble in the class of economies studied in this paper. At one extreme, high values of the collateral parameter $\lambda$ guarantee perfect capital mobility, which, in turn, ensures a unique, rapid, and smooth balanced growth path. At the other extreme, complete financial autarky, that is, a combination of no collateral and no unsecured lending, leads to macroeconomic disaster. The unique outcome in this case is slow, inefficient, and highly volatile growth with strong history dependence.

In between the two extremes of perfect mobility and no mobility lie the relevant cases of modest collateral and unsecured lending. Secured lending by itself tends to generate limit cycles as the sectoral distribution of equity shifts in response to persistent changes in relative factor productivities. TFP and the aggregate growth rate do well when most equity is in the hands of highly productive firms and less well when most equity is owned by low-productivity firms. Lower values of the collateral parameter $\lambda$ typically reduce the average growth rate, increase its dispersion, and raise the periodicity of the limit cycle.

Unsecured lending is another potential source of volatility because it is heavily influenced by the bubble-like value of a borrower's reputation. In principle, cyclical movements in credit can be smoothed out if enough unsecured lending is available to productive firms. Socially desirable balanced growth paths are still open to economies with modest collateral and substantial lines of unsecured credit. Indeed, we find that lower values of the collateral parameter $\lambda$ raise the volume of unsecured credit, which actually exceeds the corresponding decline in secured credit. Intuitively, reputation is much more valuable, and hence unsecured borrowing more sustainable, when secured lending is scarce. The downside of this situation is that, as in most bubbles, unsecured lending causes fragile multiple equilibria based on the borrower's "reputation," that is, the willingness to repay a current loan. This willingness, in turn, rests on the borrower's faith that unsecured credit will continue to be available in the future. Any event that shakes this faith (more precisely, any event that reduces expected future debt limits for all borrowers) will gradually reduce reputational borrowing until it vanishes altogether.

The rest of this paper is organized as follows. Section 2 describes a general class of economies with financial frictions. Stationary Markov equilibria are defined in Section 3 and described in Section 4 for economies with secured loans only. Section 5 looks at the dynamics of unsecured lending. Section 6 explores the predictive power of our model. It connects our theoretical results with the business cycle facts mentioned in the preceding and presents some numerical examples connecting macroeconomic aggregates with collateral availability and sectoral shocks. Conclusions about the dynamics of credit, the impact of financial reforms, and the wider research agenda suggested by the capital misallocation literature are summarized in Section 7. Proofs for all propositions are contained in the earlier working paper version [Azariadis and Kaas (2009)]. 


\section{THE ENVIRONMENT}

Consider a growth model in discrete time $t=0,1,2, \ldots$ with a finite number of agent types or sectors indexed $i \in \mathcal{I}=\{1,2, \ldots, I\}$ and productivity states $s \in \mathcal{S}=\{1,2, \ldots, S\}$. Each sector comprises a continuum of agents with equal size. All agents produce the same good, which is available for consumption and investment purposes. Their common preferences over consumption streams are represented by an additively separable expected utility function,

$$
E_{0}(1-\beta) \sum_{t=0}^{\infty} \beta^{t} \ln \left[c\left(s^{t}\right)\right]
$$

where $s^{t}=\left(s_{t}, \ldots, s_{0}\right) \in \mathcal{S}^{1+t}$ is the state history in period $t$, and the initial state $s_{0}$ is given. The productivity state follows a Markov process with transition probability from $s$ to $s_{+}$equal to $\pi\left(s_{+} \mid s\right)$. In state $s$ an agent of type $i$ can convert capital into gross output ("resources") with linear technology $y=A_{s}^{i} k$. Resources $y$ include current output and undepreciated capital, which can be costlessly converted into the single consumption/investment good in the following period. In particular, capital investment is not producer-specific. Assuming that all agents produce the same good isolates the impact of sectoral shocks on capital reallocation while abstracting from relative price effects.

We assume that the economy's production possibility frontier is constant at $A \equiv \max _{i \in \mathcal{I}} A_{s}^{i}$ for all $s \in \mathcal{S}$. Though we do not need to consider symmetric agent types, the exposition becomes simpler if we assume that every agent has access to the technological frontier sometimes and that there is always a unique most productive sector:

(A.1) Every agent operates the technological frontier sometimes; that is, for each $i$ there exists $s$ such that $A_{s}^{i}=A$.

(A.2) Not more than one agent type operates the technological frontier; that is, for each $s$ there is exactly one $i$ such that $A_{s}^{i}=A$.

Throughout this paper we focus on stationary Markov equilibria where all endogenous variables depend only on the current state vector of the economy, denoted $\sigma \equiv(\mathbf{x}, s) \in \Sigma \equiv[0,1]^{I} \times \mathcal{S}$, where $\mathbf{x}=\left(x^{1}, \ldots, x^{I}\right)$ is the vector of wealth shares owned by agent types and $\sum_{i=1}^{I} x^{i}=1$.

Each period, less productive agents lend out capital to more productive agents at the gross interest rate $R(\sigma)$ that prevails in the credit market. An exogenous fraction $\lambda \in[0,1]$ of each agent's resources is pledgeable collateral, which can be seized by creditors in the event of default. The value of $\lambda$ is constant and common for all producers; it depends on informational and technological factors such as the observability of income and wealth, as well as on creditor rights and other aspects of economic institutions. Timing within each period is as follows. First the productivity state is realized; second the credit market opens and agents produce; 
third, borrowers redeem their debt and all agents consume and carry their wealth into the next period.

Borrowers may choose to default at the end of the period. Any agent who does so loses the collateral share of his resources to creditors and is banned from unsecured borrowing in all future periods. A defaulter is still allowed to lend, however, and also retains full access to secured loans. Because no uncertainty is resolved during debt contracts (that is, borrowing and debt redemption happen within the same period), there exist default-deterring debt limits, defined as in the pure-exchange model of Alvarez and Jermann (2000). These limits are the highest values of debt preventing default. In the absence of collateral $(\lambda=0)$, our enforcement mechanism resembles the one discussed by Bulow and Rogoff (1989) and Hellwig and Lorenzoni (2009), who consider unsecured loans and assume that defaulters are denied access to future loans but are still allowed to accumulate assets. With $\lambda>0$, secured borrowing is feasible and sometimes, but not always, borrowing limits go beyond an agent's collateral capacity and sustain a greater flow of credit. Borrowing above one's collateral implies an unsecured loan founded on a producer's desire to maintain a record of solvency and of continued access to future unsecured loans.

We denote the endogenous constraint on borrower $i$ 's debt-equity ratio by $\theta^{i}(\sigma)$. Whenever capital cost $R(\sigma)$ is strictly less than borrower $i$ 's productivity $A_{s}^{i}$, this producer borrows up to his debt limit, and the leveraged equity return is $\tilde{R}^{i}(\sigma)=A_{s}^{i}+\theta^{i}(\sigma)\left[A_{s}^{i}-R(\sigma)\right]$. On the other hand, if agent $i$ 's productivity is less than or equal to the capital yield $R(\sigma)$, this agent's equity return is simply $\tilde{R}^{i}(\sigma)=R(\sigma)$. A defaulting agent, who has access only to secured (collateral) loans, faces a maximal debt-equity ratio with the property that $\theta R(\sigma)=\lambda A(1+\theta)$. Therefore, $\theta_{c}^{i}(\sigma)=\lambda A_{s}^{i} /\left[R(\sigma)-\lambda A_{s}^{i}\right]$, and his equity return is $\tilde{R}_{c}^{i}(\sigma)=A_{s}^{i} R(\sigma)(1-\lambda) /\left[R(\sigma)-\lambda A_{s}^{i}\right]$ when $R(\sigma)<A_{s}^{i}$, and $\tilde{R}_{c}^{i}(\sigma)=R(\sigma)$ otherwise.

With this notation, we can write the budget constraint of a (solvent) producer as

$$
c^{i}(\sigma)+e^{i}\left(\sigma_{+}\right)=\tilde{R}^{i}(\sigma) e^{i}(\sigma)
$$

where $e^{i}(\sigma)$ is equity. The assumption of logarithmic utility implies that all agents consume a fraction $1-\beta$ of end-of-period wealth $\omega^{i}(\sigma)=\tilde{R}^{i}(\sigma) e^{i}(\sigma)$. Furthermore, the expected utility of a productive borrower with end-of-period wealth $\omega$ can be expressed in the form $\ln (\omega)+V^{i}(\sigma)$, where $V^{i}(\sigma)$ is the utility of agent $i$ with unit wealth when the current state is $\sigma=(\mathbf{x}, s)$. Similarly, if agent $i$ had defaulted in this or in some earlier period, his utility would be expressed as $\ln (\omega)+V_{c}^{i}(\sigma)$, where $V_{c}^{i}(\sigma)$ denotes the end-of-period utility of a unit-wealth agent of type $i$ who has access to secured loans only. It is worth noting that intraperiod credit is the only traded asset in this economy. If agents were to trade insurance or contingent claims against the next period's productivity state, these securities would not be traded. ${ }^{4}$ 


\section{STATIONARY MARKOV EQUILIBRIUM}

A stationary Markov equilibrium is a list of functions,

$$
\left[c^{i}(\sigma), e^{i}(\sigma), \theta^{i}(\sigma), R(\sigma), \tilde{R}^{i}(\sigma), \tilde{R}_{c}^{i}(\sigma), v^{i}(\sigma), X^{i}(\sigma)\right]_{i \in \mathcal{I}, \sigma \in \Sigma},
$$

with the usual properties: Households treat debt limits and yields as given and maximize expected utility subjective to the budget constraints (1). In addition, all markets clear, and the debt-equity ratios $\theta^{i}(\sigma)$ are the highest possible values that will deter default for all consumers in all event histories. The returns $\left(R, \tilde{R}^{i}, \tilde{R}_{c}^{i}\right)$ are, respectively, the cost of capital and the equity returns for solvent and bankrupt agents. The functions $v^{i}(\sigma)=V^{i}(\sigma)-V_{c}^{i}(\sigma)$ define the "penalty of default" for agent $i$, that is, the difference between the continuation utilities from solvency and default. Finally, the maps $x_{+}^{i}=X^{i}(\sigma): \Sigma \rightarrow[0,1]$ connect this period's state vector $(\mathbf{x}, s)$ with the next period's wealth share for every agent $i$. Let $\mathbf{X}=\left(X^{i}\right)_{i \in \mathcal{I}}: \Sigma \rightarrow[0,1]^{I}$ be the collection of these maps.

Default-deferring debt limits leave any borrower with equity $e$ indifferent between solvency and default:

$$
\ln \left[\tilde{R}^{i}(\sigma) e\right]+V^{i}(\sigma)=\ln \left\{(1-\lambda) A_{s}^{i}\left[1+\theta^{i}(\sigma)\right] e\right\}+V_{c}^{i}(\sigma) .
$$

Here, the right-hand side is the expected utility of the defaulting agent $i$, who leaves the default period with unpledged wealth $(1-\lambda) A_{s}^{i}\left[1+\theta^{i}(\sigma)\right] e$. This equality is conveniently equivalent to

$$
\theta^{i}(\sigma)=\frac{\left(e^{v^{i}(\sigma)}-1+\lambda\right) A_{s}^{i}}{(1-\lambda) A_{s}^{i}-e^{v^{i}(\sigma)}\left[A_{s}^{i}-R(\sigma)\right]} .
$$

Equation (3) shows that the maximum default-free debt-equity ratio is increasing in the penalty for default $v^{i}(\sigma)$ and in the collateral share $\lambda$. Debt-equity ratios are also decreasing in the interest rate. Equation (3) also says that $\theta^{i}(\sigma)$ is larger than the secured borrowing limit $\theta_{c}^{i}(\sigma)=\lambda A_{s}^{i} /\left[R(\sigma)-\lambda A_{s}^{i}\right]$ for all positive default penalties $v^{i}(\sigma)>0$; it reduces to $\theta_{c}^{i}(\sigma)$ if $v^{i}(\sigma)=0$. In what follows, we refer to an equilibrium with $v^{i}(\sigma)=0$ for all $i \in \mathcal{I}$ and $\sigma \in \Sigma$ as one of secured borrowing; an equilibrium where $v^{i}(\sigma)>0$ for at least some $i \in \mathcal{I}$ and $\sigma \in \Sigma$ has both secured and unsecured borrowing with debt limits that reflect both collateral and reputation.

With aggregate capital $K$, agent $i$ 's equity is $x^{i} K$. The supply of credit comes from all agents with productivity $A_{s}^{i} \leq R(\sigma)$; because agents with $A_{s}^{i}=R(\sigma)$ are indifferent between lending and borrowing at the market rate $R(\sigma)$, the aggregate supply of credit per unit of aggregate capital is a step function, expressed as the correspondence

$$
\operatorname{CS}(\sigma)=\left[\sum_{i: A_{s}^{i}<R(\sigma)} x^{i}, \sum_{i: A_{s}^{i} \leq R(\sigma)} x^{i}\right] .
$$


Similarly, the demand for credit per unit of capital is the correspondence

$$
\mathrm{CD}(\sigma)=\left[\sum_{i: A_{s}^{i}>R(\sigma)} \theta^{i}(\sigma) x^{i}, \sum_{i: A_{s}^{i} \geq R(\sigma)} \theta^{i}(\sigma) x^{i}\right]
$$

and the credit market is in equilibrium if the two correspondences cross, that is,

$$
\mathrm{CS}(\sigma) \cap \mathrm{CD}(\sigma) \neq \varnothing
$$

As we saw earlier, for any interest yield $R(\sigma)$, the equity return for agent $i$ is

$$
\tilde{R}^{i}(\sigma)=\max \left\{A_{s}^{i}+\theta^{i}(\sigma)\left[A_{s}^{i}-R(\sigma)\right], R(\sigma)\right\},
$$

whereas the equity return for a producer with access to secured borrowing is

$$
\tilde{R}_{c}^{i}(\sigma)=\max \left\{\frac{A_{s}^{i} R(\sigma)(1-\lambda)}{R(\sigma)-\lambda A_{s}^{i}}, R(\sigma)\right\} .
$$

Agent $i$ 's wealth share changes from $x^{i}$ to

$$
x_{+}^{i}=X^{i}(\sigma)=\frac{\tilde{R}^{i}(\sigma) x^{i}}{\sum_{j \in \mathcal{I}} \tilde{R}^{j}(\sigma) x^{j}}, \sigma=\left(x^{1}, \ldots, x^{I}, s\right) .
$$

Expected utilities satisfy the recursive equations

$$
\begin{aligned}
& V^{i}(\mathbf{x}, s)=(1-\beta) \ln (1-\beta)+\beta \sum_{s_{+} \in \mathcal{S}} \pi\left(s_{+} \mid s\right)\left\{\ln \left[\beta \tilde{R}^{i}\left[\mathbf{X}(\mathbf{x}, s), s_{+}\right]\right]\right. \\
& \left.\quad+V^{i}\left[\mathbf{X}(\mathbf{x}, s), s_{+}\right]\right\} .
\end{aligned}
$$

Note again that $V^{i}$ denotes the expected utility of solvent agent $i$ with unit wealth. In the current period, this agent consumes $c=1-\beta$, and so the first term on the right-hand side is the utility of current consumption; the other terms are discounted future payoffs. In the next period, the distribution of wealth changes from $\mathbf{x}$ to $\mathbf{x}_{+}=\mathbf{X}(\mathbf{x}, s)$ and the productivity state changes from $s$ to $s_{+}$with probability $\pi\left(s_{+} \mid s\right)$; the agent saves a fraction $\beta$ of his unit wealth, ending the period with wealth $\omega_{+}=\beta \tilde{R}^{i}\left(\mathbf{x}_{+}, s_{+}\right)$and utility $\ln \left(\omega_{+}\right)+V^{i}\left[\mathbf{x}_{+}, s_{+}\right]$.

For an agent who has opted to default in some earlier period, the recursive equation in $V_{c}^{i}$ is nearly identical to (8); all that changes is that the equity returns $\tilde{R}^{i}$ are replaced by the defaulter's lower returns $\tilde{R}_{c}^{i}$. By subtracting those equations from (8), we obtain recursive equations in the default penalties $v^{i}(\sigma)=V^{i}(\sigma)-$ $V_{c}^{i}(\sigma)$ :

$$
v^{i}(\mathbf{x}, s)=\beta \sum_{s_{+} \in \mathcal{S}} \pi\left(s_{+} \mid s\right)\left\{\ln \frac{\tilde{R}^{i}\left[\mathbf{X}(\mathbf{x}, s), s_{+}\right]}{\tilde{R}_{c}^{i}\left[\mathbf{X}(\mathbf{x}, s), s_{+}\right]}+v^{i}\left[\mathbf{X}(\mathbf{x}, s), s_{+}\right]\right\} .
$$


DEFINITION 1. A stationary Markov equilibrium is a list of functions specified in (2) that satisfies equations (3)-(7) and (9) for all $\sigma=(\mathbf{x}, s) \in \Sigma$ and $i \in \mathcal{I}$.

In a stationary Markov equilibrium, the state vector $\sigma$ is also a sufficient statistic for the growth rate that connects aggregate current resources $Y$ with the previous period's resources $Y_{-}$. In particular, current aggregate capital $K$ equals saving $\beta Y_{-}$, and current resources are the sum of resources across all agent types:

$$
Y=K \sum_{i \in \mathcal{I}} x^{i} \tilde{R}^{i}(\sigma)=\beta Y_{-}\left\{R(\sigma)+\sum_{i: A_{s}^{i}>R(\sigma)}\left[A_{s}^{i}-R(\sigma)\right] x^{i}\left[1+\theta^{i}(\sigma)\right]\right\} .
$$

The growth factor is

$$
\frac{Y}{Y_{-}}=\beta\left\{\sum_{i: A_{s}^{i} \geq R(\sigma)} A_{s}^{i} x^{i}\left[1+\theta^{i}(\sigma)\right]\right\} \leq \beta A .
$$

This equation shows that the sectoral growth factor is $\beta$ times a weighted average of sectoral productivities; it has the upper bound $\beta A$, achieved when no capital is misallocated.

Before we analyze stationary Markov equilibria in detail for some special cases, we state two general results. One of them says that an equilibrium with no unsecured borrowing always exists. In particular,

PROPOSITION 1. There exists a unique equilibrium in which all borrowing is secured.

This result, which has the flavor of a no-bubble equilibrium in overlappinggenerations economies with fiat money or public debt, generalizes earlier findings by Bulow and Rogoff (1989) and Kehoe and Levine (1993). They showed that financial autarky is a no-bubble equilibrium in economies where all borrowing is unsecured simply because borrowers expect that unsecured loans will be unavailable in the future. Indeed, it is easy to check that $v^{i}(\sigma)=0$, together with $\tilde{R}^{i}(\sigma)=\tilde{R}_{c}^{i}(\sigma)$ and $\theta^{i}(\sigma)=\theta_{c}^{i}(\sigma)$, satisfies all equilibrium equations except market clearing for any given interest rate $R(\sigma)$.

What is the intuition for the equilibrium without unsecured borrowing? If there are no unsecured loans, there is no penalty for default, and therefore no borrower is permitted to borrow in excess of collateral. And conversely, when debt-equity limits just reflect collateral constraints, a good credit record is worthless because there is no default penalty. Section 4 characterizes the secured borrowing equilibrium completely for a symmetric economy with two agent types and two states.

Our second result says that the first-best allocation, which directs all capital to the most efficient producer and equalizes the marginal rate of substitution for all consumers, can only be an equilibrium if there is enough collateral. Specifically, 
$\lambda \geq(I-1) / I$ is a necessary and sufficient condition to support the first-best outcome with secured borrowing at the symmetric initial wealth distribution $x^{i}=$ $1 / I, i \in \mathcal{I}$. Here returns, $\tilde{R}^{i}=A$, are equalized for all agents, and the secured borrowing constraint is large enough to shift all capital to the most productive sector in every state.

Can the first-best also be supported by a combination of secured and unsecured loans when $\lambda<(I-1) / I$ ? In line with earlier results by Bulow and Rogoff (1989) and Hellwig and Lorenzoni (2009), the answer to this question is no. Unsecured borrowing cannot support first-best allocations because default penalties are relatively low. The intuition for this result is as follows. In a first-best allocation, the capital cost (the interest rate) equals the capital return of borrowers. Hence there is no leverage gain, so access to loans has no value for borrowers. In turn, every borrower would default on an unsecured loan, no matter how small it is. These findings are summed up in

PROPOSITION 2. When $\lambda \geq(I-1) / I$, the secured-borrowing equilibrium supports a first-best allocation for some initial distribution of wealth. Conversely, when $\lambda<(I-1) / I$, no first-best allocation can be an equilibrium with secured and unsecured borrowing.

The inequality $\lambda \geq(I-1) / I$ is stringent, requiring collateral to be a large proportion of available resources, that is, gross national product plus undepreciated capital. In spite of Proposition 2, we will see in Section 5 that unsecured borrowing can still sometimes support production-efficient allocations (that is, all capital goes to the most efficient producer, but marginal rates of substitution may not be equal for all consumers), particularly in economies with very patient agents and large productivity differences between sectors.

To explore equilibrium with binding constraints, we simplify our state space and reduce the distribution of wealth to a scalar. To achieve this, we focus in the remainder of this paper on the symmetric two-agent, two-state special case of our general environment. In particular, $A_{s}^{i}=A$ if $i=s$, and $A_{s}^{i}=z A$ if $i \neq s$, for $i \in\{1,2\}$ and $s \in\{1,2\}$, where $z<1$ is a measure of the productivity differential. Both types are equally likely to operate the frontier technology, where $\pi$ is the common probability that state $s=1,2$ does not change from one period to the next. In this symmetric economy, stationary Markov equilibria are also symmetric. Therefore, the only relevant state variable is the share of wealth owned by the borrowing agents (for short, "borrower wealth"), denoted as $x \in[0,1]$. The wealth distribution is thus $(x, 1-x)$ if $s=1$ and $(1-x, x)$ if $s=2$. Current rates of return and debt limits depend on borrower wealth $x$ alone, and the productivity state $s$ matters only for the transitional dynamics of borrower wealth.

\section{THE ROLE OF COLLATERAL}

In the equilibrium with secured borrowing, the debt-equity ratio can be read from equation (3) by setting $v^{i}(\sigma)=0$. Doing so leads to $\theta=\lambda A /[R-\lambda A]$; then the 
market-clearing loan yield becomes

$$
R(x)= \begin{cases}z A & \text { if } x \leq 1-\frac{\lambda}{z} \\ \frac{\lambda A}{1-x} & \text { if } x \in\left[1-\frac{\lambda}{z}, 1-\lambda\right] \\ A & \text { if } x \geq 1-\lambda\end{cases}
$$

When borrower wealth is less than $1-\lambda / z$, credit demand is so low that the equilibrium interest rate makes unproductive lenders indifferent between production and lending. The economy is production-inefficient because it assigns part of its capital to the bad technology. When borrower wealth exceeds that threshold, all capital flows to the more productive agents and the economy becomes productionefficient. For $x<1-\lambda$, borrowers are still debt-constrained and enjoy a higher equity yield than do lenders. Consumption growth rates are higher for borrowers than for lenders, which makes the economy consumption-inefficient. Full efficiency in both production and consumption is attained in period $t$ only when borrower wealth exceeds $1-\lambda$. In what follows, we assume throughout that $\lambda<z$, so that production inefficiency remains a possibility.

The transitional dynamics of borrower wealth is described by two maps. The next period's borrower wealth is $x_{+}=X_{0}(x)$ when the productivity state is unaltered, and it is $x_{+}=X_{1}(x)=1-X_{0}(x)$ when the productivity state changes. Using the preceding expressions for $R(x), \theta(x)=\lambda A /[R(x)-\lambda A]$ and the borrowers' equity return $\tilde{R}(x)=A+\theta(x)[A-R(x)]$, we obtain

$$
X_{0}(x)=\frac{\tilde{R}(x) x}{\tilde{R}(x) x+R(x)(1-x)}= \begin{cases}\frac{(1-\lambda) x}{(1-z) x+z-\lambda} & x \leq 1-\frac{\lambda}{z}, \\ 1-\lambda & x \in\left[1-\frac{\lambda}{z}, 1-\lambda\right], \\ x & x \geq 1-\lambda .\end{cases}
$$

Figure 1 shows the two maps $X_{0}$ and $X_{1}$ in three generic situations. These graphs show that the stochastic dynamics of borrower wealth must settle down in the bounded interval $[\lambda, 1-\lambda]$ or $[1-\lambda, \lambda]$. Moreover, the asymptotic dynamics must be a stochastic cycle with finite support. The precise statement is

PROPOSITION 3. In the equilibrium with secured borrowing only and for any $\pi \in(0,1)$ and $\lambda>0$, the dynamics of wealth $x_{t}$ converges to a finite stochastic cycle $\left(x_{n}\right)_{n=1}^{N}$ with probability one as $t \rightarrow \infty$. The cycle has the following features.

(a) Economies with ample collateral $\lambda \geq 1 / 2$ converge to a cycle with two states $x_{2}=1-x_{1} \in[1-\lambda, \lambda]$. Production is efficient, debt constraints do not bind, households maintain constant wealth shares, and aggregate output and individual consumption grow at the constant rate $\beta$ A.

(b) Economies with medium collateral $\lambda \in[z /(1+z), 1 / 2)$ also converge to a cycle with two states and $x_{1}=\lambda<x_{2}=1-\lambda$. Production is again efficient and aggregate growth is constant at $\beta$ A. However, individual consumption and wealth growth rates are volatile, and borrowers are constrained for a fraction $1-\pi$ of periods. Specifically, agent $i$ 's consumption growth in state $s_{t}$ is $\beta A$ if $s_{t}=s_{t-1}$, $\beta A \lambda /(1-\lambda)$ if $i \neq s_{t} \neq s_{t-1}$, and $\beta A(1-\lambda) / \lambda$ if $i=s_{t} \neq s_{t-1}$. 


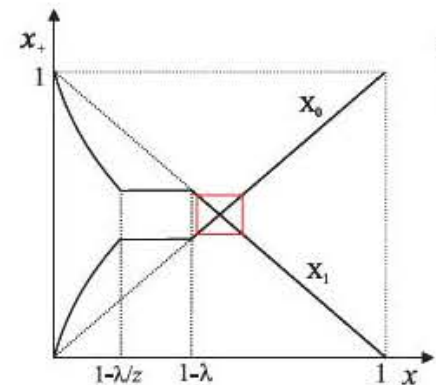

(a) $\lambda \geq 1 / 2$

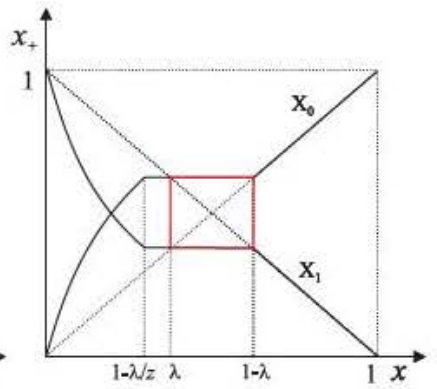

(b) $1 / 2>\lambda \geq z /(1+z)$

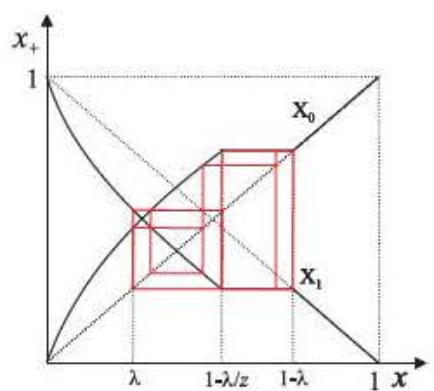

(c) $\lambda<z /(1+z)$

FIGURE 1. Asymptotic cycles with secured borrowing.

(c) Economies with small collateral $\lambda<\frac{z}{1+z}$ converge to a cycle with generically $N=2 m$ states, with $m \geq 2$. In $2 m-3$ of these states, aggregate growth is lower than $\beta A$. Cycles are typically asymmetric, with booms lasting longer than recessions. The number of states is a weakly decreasing function of $\lambda$, and $m \rightarrow \infty$ as $\lambda \rightarrow 0$.

Figure 1 illustrates the three possibilities stated in the proposition. In Figure 1a, the typical first-best equilibrium is a cycle where borrower wealth fluctuates between two states, which means that every agent's wealth share is constant. Any initial wealth distribution must enter such a cycle with probability one in finitely many periods. In Figure $1 \mathrm{~b}$, the stochastic cycle again has only two states, but now one of them has constrained borrowers; no capital is misallocated and production is efficient in all periods. Figure 1c shows an example of a cycle with six states, with no misallocation of capital in three of them, and some misallocation in the other three. The red lines indicate the possible transitions between these states; dynamics in this case is complicated because of the discrepancy of returns between productive and unproductive agents, which induces volatility in wealth shares.

An immediate implication of this analysis is that the dispersion of output growth is magnified when the collateral share falls. This is again evident from Figure 1c: the support of the invariant cycle becomes larger, the smaller the value of $\lambda$ is. 
Lower values of collateral not only reduce the trend growth rate, but also lead to a more complex and dispersed distribution of growth rates around trend. In fact, in the limit where $\lambda \rightarrow 0$, the economy does not even have a finite limit cycle but is instead described by a stochastic process on a countably infinite state space.

Proposition 3 spells good news for financial innovations in search of instruments that collateralize returns from airports, highways, bridges, and other items of infrastructure. An abundance of collateral contributes to faster and more predictable growth. The opposite can be said, in principle, of financial reforms that protect from creditors, at least for short periods of time, primary residences, and other forces of private capital.

\section{THE DYNAMICS OF UNSECURED LENDING}

\subsection{Unsecured Loans Only}

Before we describe the interaction of secured and unsecured lending, we summarize and adapt to our economy some key findings about exchange economies from Kehoe and Levine (1993), Alvarez and Jermann (2000), and Hellwig and Lorenzoni (2009). All these papers explore self-enforcing loans whose only backing is a threat to cut off defaulters from future loans in perpetuity. The first two papers impose the additional penalty of prohibiting future lending as well as borrowing. In either case, credit is a bubble that rests on self-fulfilling debt-equity limits such as those specified by (3) for the special case $\lambda=0$. Bubbly equilibria, which correspond to positive debt-equity ratios, require enduring beliefs in favorable future credit conditions sustaining positive values of reputation $v>0$. These favorable equilibria coexist with worse ones in which the unsecured credit bubble bursts and leverage vanishes asymptotically in response to pessimistic but fully rational beliefs about worsening credit conditions. Typically, determinate equilibria with a high debt-equity ratio $\theta^{i}(\sigma)$ coexist with indeterminate equilibria in which $\theta^{i}(\sigma)$ converges to zero. The following subsection provides details about the dynamics of credit, and Section 7 describes some of the policy issues that arise from the coexistence of good and bad equilibria.

\subsection{Interactions of Secured with Unsecured Loans}

Equilibria with simultaneous secured and unsecured borrowing are not easy to describe analytically in any degree of generality because changes in the distribution of wealth greatly complicate the dynamics of credit. Nonetheless, it is possible to derive a few insightful results for some special cases where the asymptotic wealth dynamics settles down to a finite state space. One such case is the deterministic economy $(\pi=0)$, with two alternating productivity states, explored in Section 4. A related working paper [Azariadis and Kaas (2009)] studies stochastic cycles with Markovian productivity shocks. 
The deterministic economy with $\pi=0$ admits a steady state with binding constraints where borrower wealth remains constant at some $x$. The wealth share of either type thus periodically alternates between $x$ and $1-x$. This is in stark contrast to the stochastic economy where equilibria are typically cyclical and the only possible steady state is a first-best outcome, which can be achieved only if $\lambda \geq 1 / 2$. For $\lambda<1 / 2$, borrower wealth must fluctuate permanently in the stochastic economy with $\pi>0$.

One obvious steady state is the one with secured borrowing only. It is straightforward to extend Proposition 3 to the deterministic case as follows. The deterministic economy has a unique steady state $x$ with secured borrowing which is (i) firstbest when $\lambda \geq 1 / 2$; (ii) production-efficient and consumption-inefficient when $z /(1+z) \leq \lambda<1 / 2$; and (iii) production-inefficient when $\lambda<z /(1+z)$. In Figure 1 these steady states are at the intersection of the $45^{\circ}$ line with the map $X_{1}$ (.). For a deterministic economy with secured and unsecured borrowing, we have the following result. that

PROPOSITION 4. Let $\pi=0$. Then there is a threshold value $\hat{\lambda} \leq \frac{z-\beta^{2}}{1-\beta^{2}}$ such

(a) If $\beta \leq z$, there is one steady state with secured borrowing and no steady state with secured and unsecured borrowing.

(b) If $\beta>z$ and $\lambda \in\left[\hat{\lambda}, \frac{\beta}{1+\beta}\right)$, there are two steady states: one with both secured and unsecured borrowing, and another with secured borrowing only.

(c) If $\beta>z>\beta^{2}$ and $\lambda \in\left(\hat{\lambda}, \frac{z-\beta^{2}}{1-\beta^{2}}\right)$, there is a third steady state with secured and unsecured borrowing that coexists with the two other steady states of $(b)$.

To interpret these results, the inequality $\beta \leq z$ says that the gains from credit market participation are not high enough to support an equilibrium with unsecured borrowing. Part (a) extends the well-known result of Kehoe and Levine (1993) that intertemporal financial autarky or, in our setting, secured borrowing is the only equilibrium when agents are too impatient or when income fluctuations are too small. Conversely, says part (b), when $\beta>z$ unsecured borrowing is feasible but now collateral may not exceed the threshold $\beta /(1+\beta)$. If the collateral value is higher, the gain from borrowing above collateral is too small to prevent borrowers from defaulting. Put differently, secured borrowing alone supports efficient allocations with low leverage, so that extended unsecured credit limits add very little value. Part (c) establishes a strong form of equilibrium multiplicity. In these situations, one steady state is production-efficient whereas the other two steady states are production-inefficient. The explanation for multiplicity is dynamic complementarity in the sequence of endogenous borrowing limits. Borrowers' expectations of future credit market conditions affect their incentives to default today, and this in turn has an impact on their current borrowing limits. If future constraints are tight, the payoff from solvency is modest; agents place a low value on the strategy of participating in credit markets, and their default penalty is low. In this case, current default-deterring 
debt limits must be low. Conversely, expectations of loose constraints in the future make participation more valuable, lessen default incentives, and ease current constraints.

\section{NUMERICAL EXAMPLES}

For a fuller understanding of stochastic cycles, we use value function iteration to isolate stationary Markov equilibria. Specifically, let $v_{0}^{1}(x, s)$ be the initial default penalty for agent 1 conditional on $x$ being the borrower's wealth share and $s$ the state. Then for arbitrary initial default penalties $v_{0}^{1}(., 1)>0$ and $v_{0}^{1}(., 2)>0$, we calculate constraints and interest rates for all $x$ using the equilibrium conditions (3)-(6) and the wealth iteration maps (7). The results are then substituted in the right-hand side of (9) to calculate new default penalties $v_{1}^{1}(., 1)$ and $v_{1}^{1}(., 2)$, and so on. Our previous multiplicity results indicate that this map cannot be a global contraction, so one cannot expect a definitive proof that equilibrium exists. We find, however, that these iterations converge fast, and we are able to identify the theoretical equilibria in the special cases analyzed in previous sections. We conjecture that the iteration procedure generally converges to the determinate equilibrium whenever there is equilibrium multiplicity. ${ }^{6}$

For a plausible benchmark parameterization, we study how growth and volatility depend on the model parameters and how they correlate with the sectoral dispersions of equity returns and TFP. We fix the three parameters $A=1.08$, $\beta=0.96$, and $\pi=0.9$ so that annual growth in the first-best economy is at $3.7 \%$ and sectoral productivity shifts are rather persistent, with a mean duration of 10 years. We then explore how the features of the economy change when we vary the key parameters $\lambda$ and $z$.

Figure 2 shows the result of the parameter variation as $\lambda$ goes from zero to $1 / 2$ when $z$ is fixed at 0.85 . From Proposition 3 it follows that the economy is production-efficient (so aggregate growth is constant at $\beta A$ ) when $\lambda \geq z /(1+z) \approx$ 0.46 , and this outcome is achieved by secured borrowing, which is the unique equilibrium. As the collateral share $\lambda$ falls below that value, the growth rate decreases and becomes more volatile. When $\lambda$ falls below 0.41 , secured borrowing ceases to be the unique equilibrium. At this point another equilibrium emerges that combines secured and unsecured borrowing and supports faster and stabler output growth than the pure-collateral equilibrium. For lower values of $\lambda$, the differences between these equilibria are substantial: at $\lambda=0.2$, the collapse of unsecured lending would trigger a fall in output growth from about $3.5 \%$ to less than $0.5 \%$, and the standard deviation of output growth would rise from just $0.5 \%$ to over $4 \%$. Another interesting observation is that a reduction in the collateral share $\lambda$ has opposite effects in equilibria with and without unsecured borrowing. At the purecollateral equilibrium, a lower value of $\lambda$ clearly leads to lower and more volatile growth because less capital is shifted to the most productive sectors. However, when we add unsecured borrowing, less collateral makes reputation more valuable 

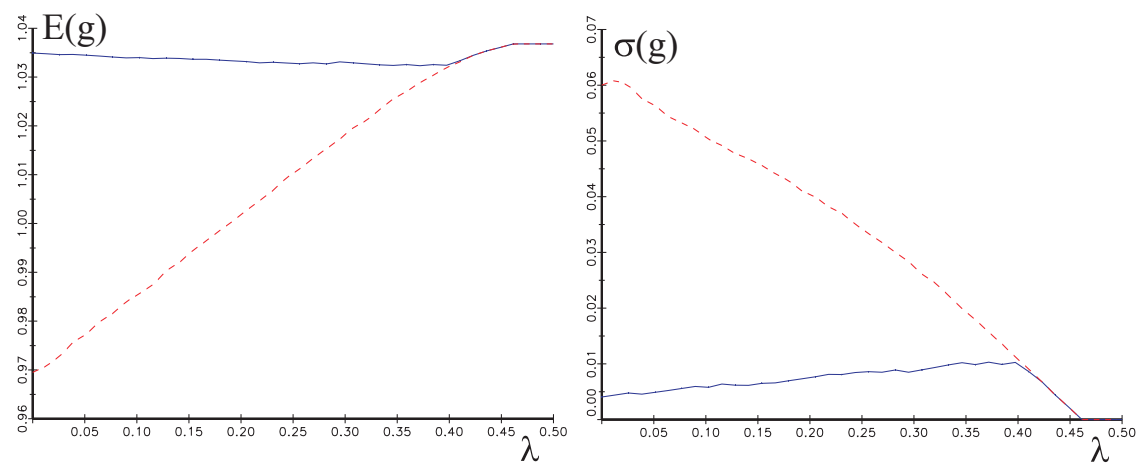

FigURE 2. Mean and standard deviation of growth as $\lambda$ varies from 0 to 0.5 , where $A=1.08, \beta=0.96, \pi=0.9$, and $z=0.85$. The secured-borrowing equilibrium is shown by the dashed curve, and the equilibrium with secured and unsecured borrowing is solid. $E(g)$ and $\sigma(g)$ are calculated as sample averages for a time series of 50,000 periods.

because the potential exclusion from unsecured loans is more harmful; thus, credit limits are relaxed, and growth increases and becomes less volatile.

Figure 3 shows the result of a similar simulation when $\lambda$ is fixed at 0.2 and $z$ varies from 0.6 to 1.0 . Clearly, when $z$ is close to one, the economy is almost first-best and growth is constant at $\beta A \approx 1.037$. For values of $z$ above 0.94 , there is a unique equilibrium with secured borrowing; a second equilibrium with unsecured borrowing emerges for a larger productivity spread between the two sectors. Interestingly, unsecured borrowing permits a more efficient allocation of capital when the productivity difference between the two sectors is larger. Indeed,
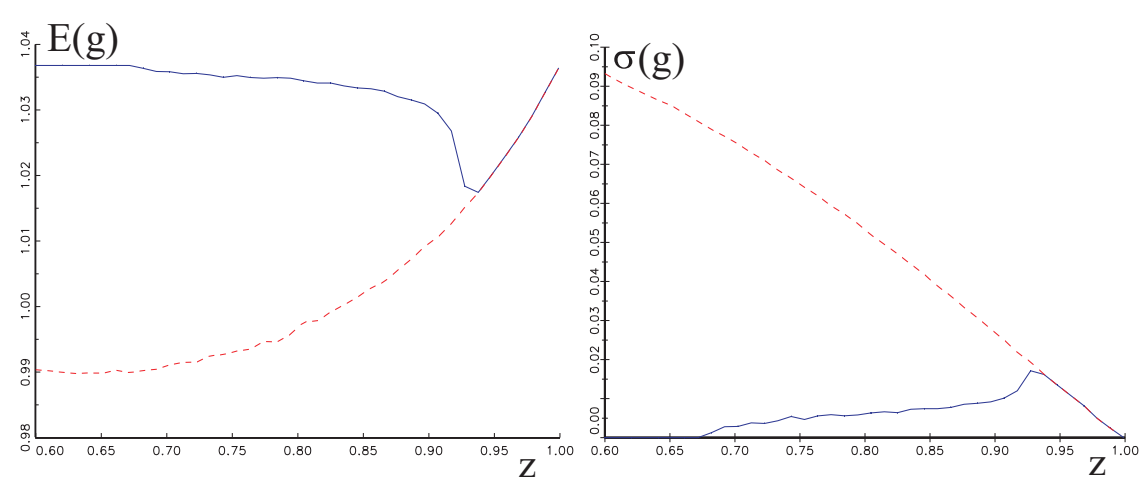

FIGURE 3. Mean and standard deviation of growth as $z$ varies from 0.6 to 1 , where $A=1.08$, $\beta=0.96, \pi=0.9$, and $\lambda=0.2$. The secured-borrowing equilibrium is shown by the dashed curve, and the equilibrium with secured and unsecured borrowing is solid. $E(g)$ and $\sigma(g)$ are calculated as sample averages for a time series of 50,000 periods. 
the equilibrium with secured and unsecured borrowing achieves a productionefficient allocation of resources for values of $z$ below 0.67 .

At the benchmark parameter values with $\lambda=0.2$ and $z=0.85$, we also calculate equity return dispersion as the spread between sectoral equity returns, measured by the wealth-weighted standard deviation between $\tilde{R}_{t}^{1}$ and $\tilde{R}_{t}^{2}$. At the "good" equilibrium with secured and unsecured borrowing, we find that this measure averages around 5.4\% and has a standard deviation of 7\%, the same order of magnitude as the stock-market dispersion indices reported in Loungani et al. (1990, Figure 1). The coefficient of correlation between equity-return dispersion and $g_{t}$ is -0.80 , which is in line with the evidence listed in the Introduction. Growth is low when capital is misallocated in which case the dispersion between sectoral equity returns is large.

In accordance with results of Eisfeldt and Rampini (2006, Table 3), our model further produces countercyclicality of TFP dispersion across sectors. Using the standard deviation of sectoral factor productivities $A$ and $z A$, weighted by their relative output shares, as a measure of TFP dispersion, we find a mean dispersion of $2.5 \%$, a standard deviation of $4.1 \%$, and a contemporaneous correlation with growth of -0.96 .

\section{SUMMARY, EXTENSIONS, AND CONCLUSIONS}

This paper outlines a financial theory of aggregate productivity that connects the sectoral allocation of capital with sectoral productivity shocks and credit frictions. We emphasize frictions arising from insufficient collateral for secured loans and from the limited enforcement of unsecured loans. Both lead to endogenous debt limits that slow the reallocation of surplus capital from less productive to more productive sectors, and prevent sectoral productivities and sectoral rates of return from becoming fully equal.

\subsection{Main Contributions}

Our focus is on the interaction between secured and unsecured lending and on the channels through which these two complementary types of credit influence capital reallocation among sectors, and therefore determine economywide movements in productivity and output. The basic observations we seek to explain are that (i) the amount of capital reallocation among firms is procyclical but the benefits from reallocation are countercyclical; (ii) the dispersions of equity returns and of sectoral total factor productivities are both countercyclical; and (iii) collateral contributes to macroeconomic stability.

Our results are consistent with all of these observations, starting with those by Eisfeldt and Rampini (2006) referred to at the end of Section 6. If we reinterpret "sectors" as individual firms, then our results are also consistent with those of Hsieh and Klenow (2009) who find that industry productivity dispersion is negatively correlated with industry productivity in a panel that includes data from the 
United States, China, and India. Alternatively, if we index countries by the ratio of collateral assets to total resources, our results are in line with those of Diebold and Yilmaz (2008), who find that macroeconomic volatility is positively correlated with stock market volatility in a cross section of countries.

The downside of our model economy is a complex theoretical structure that one can study in detail only under strong simplifying assumptions about the processes that govern individual productivities. These are typically assumed to be degenerate Markov processes. In Azariadis and Kaas (2012), we obtain more general results in a related model with idiosyncratic (as opposed to sectoral) shocks.

\subsection{The Sources of Business Cycles}

Financial mishaps are important sources of macroeconomic volatility in our economy. Among these we include the slow response of capital reallocation to sectoral shocks, which leaves too much capital invested in the wrong firms and reduces aggregate TFP; liquidity shocks to collateral values can set off or amplify cycles for exactly the same reasons, in the manner more fully described by Proposition 3.

Proposition 4, part (c), highlights another potential source of macroeconomic volatility, in the form of sunspot-like shocks that move the economy from efficient to inefficient allocations and vice versa. These movements correspond to selffulfilling changes in expected credit conditions and can cause serious damage to the economy. A clear example of volatility is the one that gripped developed economies throughout the world from 2008 to 2010. Its symptoms were a substantial fall in economic activity and steep reductions in asset prices and the volume of unsecured credit. For example, seasonally adjusted weekly averages of all commercial paper issued in the United States fell from \$170 billion for all of 2007 to just about $\$ 100$ billion for the week ending June 12, 2009. The seasonally adjusted stock of all commercial paper outstanding dropped by $20 \%$ in the six months following November 30, 2008.

Our model can also offer a simple explanation for the macroeconomic effects of financial disintermediation, interpreted as transitions from a well-intermediated, socially desirable and fragile state with plenty of unsecured credit to a poorly intermediated, less desirable but asymptotically stable state in which all loans are collateralized. The impulse for this transition is widespread skepticism about the ability of financial markets to continue the provision of unsecured credit at the volume needed to support socially desirable outcomes.

\subsection{Policy Implications}

The key policy lesson we draw for intermediation via unsecured loans is that credit in that environment is a bubble, which makes the entire financial structure fragile. In technical terms, the first welfare theorem fails in economies that admit bubbles: equilibrium may or may not be constrained efficient, and an activist 
mix of monetary and fiscal policies is a prerequisite if we wish to achieve good outcomes. This argument is further developed in Antinolfi et al. (2007).

Another route toward good equilibria is financial reforms that collateralize previously unsecured sources of income and wealth; Proposition 3 says that such reforms reduce macroeconomic volatility and eliminate long-lasting cycles. Not all financial reforms work this way; rehypothecation and some other financial innovations raise leverage by allowing a single piece of collateral to support several loan contracts, often in conjunction with default insurance and other derivative instruments. Proposition 3 clearly connects high leverage with complicated and large business cycles.

\subsection{Extensions}

Time series of secured and unsecured loans seem to be highly correlated over the business cycles. Understanding this correlation and the wider connection of loans with asset prices seems a natural extension of the literature on lending with limited commitment. Of equal, and perhaps greater, interest would be a detailed study of what it would take to convince borrowers that expected credit conditions would improve or remain strong. Macroeconomic volatility may become more tolerable if central banks can invent credit policies that credibly allay fears about adverse shocks to future lending.

\section{NOTES}

1. Intermediate inputs are misallocated because they are purchased on credit by producers who face different borrowing costs. Interestingly, Chari et al. find very little explanatory power in "investment wedges," that is, in time-varying distortions of the economywide cost of capital.

2. See Eisfeldt and Rampini (2006), who find strong countercyclical dispersion of capital productivity among firms and strong countercyclical sectoral dispersion of TFP; Loungani et al. (1990) and Brainard and Cutler (1993), who report substantial countercyclical dispersion of stock market returns across sectors; and Diebold and Yilmaz (2008), who find a positive correlation between the volatilities of stock market returns and GDP growth in a sample of 40 countries.

3. The fact that credit limits are determined endogenously by incentive constraints distinguishes this line of work from the large literature on credit market imperfections in growth models [e.g., Greenwood and Jovanovic (1990); Bencivenga and Smith (1991); Aghion and Bolton (1997)]. Moll (2009) embeds enforcement constraints in a growth model, emphasizing misallocation and inequality in an environment without shocks.

4. To see this, write the agent's budget constraint (1) as

$$
c^{i}(\sigma)+e^{i}\left(\sigma_{+}\right)+\sum_{s_{+}} q_{s_{+}}(\sigma) a_{s_{+}}^{i}(\sigma)=\tilde{R}^{i}(\sigma)\left[e^{i}(\sigma)+a_{s}^{i}\left(\sigma_{-}\right)\right],
$$

where $q_{s_{+}}(\sigma)$ is the price of a security that pays one unit in tomorrow's state $s_{+}$and nothing else, and $a_{s_{+}}^{i}(\sigma)$ is agent $i$ 's trade of this security. Then the agent's first-order condition is $q_{s_{+}}(\sigma) / c^{i}(\sigma)=$ $\beta \pi\left(s_{+} \mid s\right) \tilde{R}^{i}\left(\sigma_{+}\right) / c^{i}\left(\sigma_{+}\right)$. It is then straightforward to verify that $q_{s_{+}}(\sigma)=\pi\left(s_{+} \mid s\right)$ and $a_{s_{+}}^{i}(\sigma)=0$ solve this equation, together with $c^{i}(\sigma)=(1-\beta) \tilde{R}^{i}(\sigma) e^{i}(\sigma)$.

5. Because of symmetry, default penalties for agent 2 are simply $v^{2}(x, 1)=v^{1}(x, 2)$ and $v^{2}(x, 2)=$ $v^{1}(x, 1)$.

6. In Azariadis and Kaas (2009), we prove that at least one equilibrium is determinate if there are multiple equilibria, and simulations suggest that value function iteration converges to this equilibrium. 


\section{REFERENCES}

Aghion, P. and P. Bolton (1997) A theory of trickle-down growth and development. Review of Economic Studies 64, 151-172.

Alvarez, F. and U. Jermann (2000) Efficiency, equilibrium, and asset pricing with risk of default. Econometrica 68, 775-797.

Antinolfi, G., C. Azariadis, and J. Bullard (2007) Monetary policy as equilibrium selection. Federal Reserve of St. Louis Review 89, 331-341.

Azariadis, C. and L. Kaas (2009) Capital Misallocation and Aggregate Factor Productivity. Federal Reserve Bank of St. Louis working paper 2009-028.

Azariadis, C. and L. Kaas (2012) Self-Fulfilling Credit Cycles. Federal Reserve Bank of St. Louis working paper 2012-047A.

Bencivenga, V.R. and B. Smith (1991) Financial intermediation and endogenous growth. Review of Economic Studies 58, 195-209.

Brainard, S. and D. Cutler (1993) Sectoral shifts and cyclical unemployment reconsidered. Quarterly Journal of Economics 108, 219-243.

Bulow, J. and K. Rogoff (1989) Sovereign debt: is to forgive to forget? American Economic Review 79, 43-50.

Chari, V., P. Kehoe, and E. McGrattan (2007) Business cycle accounting. Econometrica 75, 781-836.

Diebold, F. and K. Yilmaz (2008) Macroeconomic Volatility and Stock Market Volatility, Worldwide. NBER working paper 14269.

Eisfeldt, A. and A. Rampini (2006) Capital reallocation and liquidity. Journal of Monetary Economics 53, 369-399.

Greenwood, J. and B. Jovanovic (1990) Financial development, growth, and the distribution of income. Journal of Political Economy 98, 1076-1107.

Hall, R. and C. Jones (1999) Why do some countries produce so much more output per worker than others? Quarterly Journal of Economics 114, 83-116.

Hellwig, C. and G. Lorenzoni (2009) Bubbles and self-enforcing debt. Econometrica 77, 1137-1164.

Hsieh, C.-T. and P.J. Klenow (2009) Misallocation and manufacturing productivity in China and India. Quarterly Journal of Economics 124, 1403-1448.

Kehoe, T.J. and D.K. Levine (1993) Debt-constrained asset markets. Review of Economic Studies 60, 865-888.

Kiyotaki, N. and J. Moore (1997) Credit cycles. Journal of Political Economy 105, 211-248.

Klenow, P.J. and A. Rodriguez-Clare (1997) Economic growth: A review essay. Journal of Monetary Economics 40, 597-617.

Lagos, R. (2006) A model of TFP. Review of Economic Studies 73, 983-1007.

Loungani, P., M. Rush, and W. Tave (1990) Stock market dispersion and unemployment. Journal of Monetary Economics 25, 367-388.

Moll, B. (2009) Creditor Rights, Inequality and Development in a Neoclassical Growth Model. Working paper, University of Chicago.

Parente, S. and E. Prescott (1999), Barriers to Riches. Cambridge, MA: MIT Press. 